\title{
JÓVENES RURALES: TRABAJO Y MOVILIDADES ESPACIALES EN UNA REGIÓN HORTÍCOLA EN ARGENTINA
}

\section{RURAL YOUTH: WORK AND SPACE MOBILITIES IN AN HORTICULTURAL REGION IN ARGENTINA}

\author{
Lucía Marioni* \\ Emilia Schmuck**
}

RESUMEN

En este artículo se abordan las prácticas y las representaciones acerca del trabajo y las movilidades espaciales de jóvenes de familias de pequeños productores hortícolas de Argentina. La investigación se realizó entre junio de 2016 y junio de 2017 a partir de una estrategia etnográfica. Entre los aportes se señalan la invisibilización y las desigualdades de género en el trabajo, así como, se caracterizan las movilidades espaciales cotidianas entre lo que las juventudes identifican como espacios antagónicos: "el campo" y "la ciudad".

PALABRAS CLAVE: ARGENTINA * JOVEN RURAL * TRABAJO * MUJER RURAL * HORTICULTURA

\section{ABSTRACT}

This paper presents rural youth`s practices and representations about their work and space mobilities in small producers families in Argentina. From an ethnographic methodology, the research was made from june 2016 to june 2017. The main contributions refers to invisibilization and gender inequalities at work and characterization of the daily spatial mobility between that they identify as antagonistic spaces: "the countryside" and "the city".

KEYWORDS: ARGENTINE * RURAL YOUTH * WORK * RURAL WOMEN * HORTICULTURE

* Instituto de Estudios Sociales, UnER-CONICET del Consejo Nacional de Investigaciones Científicas y Técnicas (CONICET), Argentina.

marionilucia@gmail.com

** Instituto de Estudios Sociales, UnER-CONicEt del Consejo Nacional de Investigaciones Científicas y Técnicas (CONICET), Argentina.

emilia.schmuck@gmail.com 


\section{INTRODUCCIÓN}

En el presente artículo se abordan las prácticas y las representaciones acerca del trabajo; así como, las movilidades espaciales en jóvenes pertenecientes a familias de pequeños productores del cinturón hortícola de Santa $\mathrm{Fe}$ (Argentina), en un contexto de paulatina disminución de la actividad en la zona. Estas juventudes son estudiadas en el contexto de las transformaciones sociales y productivas en el medio rural en que viven y trabajan, considerando las diferencias y desigualdades de género, así como en relación a la propia condición juvenil al interior de las familias.

A pesar de la creciente preocupación de las ciencias sociales por las juventudes, sus particularidades en los espacios rurales han sido invisibilizadas en América Latina y principalmente en Argentina. Desde una perspectiva etnográfica, este trabajo busca generar un aporte a los estudios sobre la población joven rural, considerando los contextos territoriales y situacionales específicos; así como, sus relaciones al interior de las familias a las que pertenecen.

Se inicia el artículo refiriéndose a las decisiones metodológicas tomadas en la investigación de la que deriva el presente trabajo. En segundo lugar, se realiza una aproximación a las discusiones en torno al concepto de juventudes rurales. Luego, se presentan las particularidades del cordón hortícola y las condiciones de vida de las familias de pequeños productores, partiendo de las transformaciones socio-productivas en la región pampeana. Posteriormente, se profundiza en las dimensiones consideradas: trabajo y movilidades espaciales. Por último, se comparten las reflexiones finales y las líneas de indagación para continuar el estudio.

\section{ALGUNOS APUNTES SOBRE LAS DECISIONES METODOLÓGICAS}

Este texto es resultado de un proceso investigativo realizado desde una perspectiva etnográfica. La investigación se llevó a cabo entre junio de 2016 y junio de 2017 junto a familias de pequeños productores del cordón hortícola de Santa Fe. Se valora la etnografía a partir de la convicción de que la investigación no se hace sobre una población, sino con ella y a partir de ella. Esto a su vez permite "documentar lo no-documentado" (Rockwell, 2009, p. 48) y ahondar en la comprensión de los procesos y relaciones sociales, lo que potencia el estudio de la complejidad de las realidades rurales y las familias a las que pertenecen las personas jóvenes horticultoras.

Esta perspectiva se tradujo en un seguimiento sistemático del hacer de esta población, es decir, sus actividades, rutinas e interacciones cotidianas en y a través de las cuales creaban, transformaban, deshacían y rehacían sus relaciones, prácticas, pertenencias, espacios y organizaciones (Quirós, 2015). La técnica principal fue la observación participante, la cual permite "detectar las situaciones en que se expresan y generan los universos culturales $y$ sociales en su compleja articulación y variedad" (Guber, 2001, p.56). En este sentido, se participó en ferias, trabajo en las quintas y espacios de socialización junto a las familias. Además, se realizaron entrevistas no directivas —es decir, conversaciones guiadas por preguntas abiertas a posibles derivaciones $y$ enunciados no contemplados (Guber, 2001) — a jóvenes, otros integrantes de sus familias, referentes de organizaciones de productores ${ }^{1}$ y trabajadoras de la Agencia de Extensión Rural del Instituto Nacional de Tecnología Agropecuaria (INTA) identificadas como agentes estatales con historia de trabajo en la zona ${ }^{2}$.

$1 \quad$ Cabe aclarar que, aunque un estudio más detallado del tema excede las posibilidades de este artículo, se puede señalar que la gran mayoría de las familias integran al menos una organización de productores y productoras. Aunque se advierten distintos modos de participación, en todos los casos la inclusión en estos espacios se valora por la posibilidad de asegurar ámbitos de comercialización de la producción.

2 Para preservar la identidad de las personas integrantes de las familias, se utilizaron pseudónimos en el documento. 


\section{A PROPÓSITO DE LAS JUVENTUDES RURALES ${ }^{3}$}

Una afirmación resulta incuestionable para los estudios sobre juventudes rurales en América Latina: si hay algo por lo que estas se destacan es por su poca o nula visibilidad. Esta situación tiene su correlato en el sesgo urbanocéntrico de la mayoría de las políticas públicas destinadas a las juventudes, así como, en la escasa o nula perspectiva generacional de los programas dirigidos a la población en contextos rurales. En Argentina, esta invisibilización se ve acompañada por uno de los procesos de urbanización más evidentes en la región: en el país, solo el $8,9 \%$ de la población vive en contextos rurales; el 3,2\% habita en localidades de menos de 2 mil habitantes y el restante 5,7\% pertenece a población rural dispersa (INDEC, 2010) ${ }^{4}$. En la provincia de Santa Fe, aunque la principal actividad económica está vinculada a la producción primaria, solo el 7\% habita en áreas rurales (Gobierno de la Provincia de Santa Fe, 2011).

Las juventudes rurales argentinas no emergen en la escena pública encarnando "conductas disruptivas del orden socialmente aceptado" (Bruniard y otros, 2007, p. 72), lo que sí sucede con sus pares urbanos, quienes con frecuencia protagonizan producciones mediáticas con fuerte resonancia social que inciden tanto en la agenda pública y académica como en las políticas públicas. Si puede decirse que mediante el discurso mediático se refuerzan estereotipos sociales que estigmatizan a la población joven urbana como peligrosa, pero también como desinteresada o exitosa, para señalar tres

$3 \quad$ Parte de estas reflexiones pueden encontrarse en Schmuck, M. E (2018). Juventudes en plural, territorios en transformación. Hacia un estado del arte de los estudios sobre juventudes rurales en Argentina. Revista Pós, dossiê: "Jovens pesquisadores latino-americanos", 14.

El Instituto de Estadística y Censo de Argentina (INDEC) considera que la población urbana es aquella que reside en áreas de 2 mil o más habitantes, mientras clasifica como población rural a la que se encuentra agrupada en localidades de menos de 2 mil habitantes y dispersa en campo abierto. Acerca de discusiones y propuestas en torno a la definición de "rural" con fines estadísticos, ver: Dirven, M. $y$ otros (2011). grandes condensaciones de sentido (Saintout, 2009), en cambio, las juventudes rurales en Argentina "brillan por su ausencia".

Particularmente, en el ámbito académico, aunque desde la década de 1980 en América Latina se ha desarrollado el campo de estudios sobre juventudes (Chaves, 2009), las investigaciones que presentan a jóvenes en su vinculación con el contexto rural, han sido relativamente escasas y las vulnerabilidades de lo que a grandes rasgos se podría llamar como jóvenes rurales se encuentran poco estudiadas (Kessler, 2007) ${ }^{5}$. A pesar de que en las últimas décadas, esta tendencia comienza a revertirse, se pueden señalar algunos problemas como la centralidad de trabajos que consideran a esta población en tanto actores estratégicos para el desarrollo rural, con las dificultades que conlleva en términos de generar imposiciones identitarias y referir a estos solo en tiempo futuro (Roa, 2017). Emerge, entonces, un gran desafío: generar aportes sobre estas juventudes que atiendan a las particularidades experienciales, territoriales $y$ sociales en la diversidad de los espacios sociales rurales, y que a su vez, contemplen los enfoques teóricos de la tradición de estudios de juventud.

En este trabajo se entiende que la juventud se construye socialmente y varía en cada sociedad en diferentes períodos históricos, encontrándose condicionada también por cuestiones como el género y la clase social; es un producto histórico resultado de relaciones sociales, relaciones de poder, relaciones de producción, etc. (Braslavsky, 1986; Margulis y Urresti, 1996 y 1998; Saltalamachia, 1989; Pérez, 2000 y 2004; Chaves, 2005). Por ello, al estudiar las juventudes es necesario apartarse de una mirada que se base exclusivamente en la cuestión etaria para pensarlas en sus contextos históricos y culturales específicos, lo que debe ser especialmente considerado al referirse a las juventudes rurales dado el carácter amplio, dinámico y plural de este sujeto de estudio (González y Román, 2012). En este sentido, se

\footnotetext{
5 Para un estado de la cuestión acerca de los estudios sobre juventudes rurales en América Latina, ver: Kessler, G. (2007).
} 
abordan las particularidades de las personas jóvenes rurales en sus contextos territoriales $y$ situacionales específicos, remitiendo especialmente a las relaciones articuladas al interior de sus familias.

El adjetivo "rural" que compone la categoría de juventudes rurales también debe ser problematizado. A partir de la década de 1990, el reconocimiento de la pluralidad de modos de entender la ruralidad y los procesos de urbanización impulsaron discusiones en torno a nuevas categorías como rurbanidad, rururbanidad y nuevas ruralidades (Weller, 1997; Klein, 1992; Carneiro, 1999; Graziano da Silva, 1999; Moreira, 2003), nociones que se encuentran en proceso de estudio y discusión (Garayo, 1996; Dirven et ál., 2011; Matijasevic y Ruiz, 2013). Los cambios en los procesos productivos, el acceso a la tecnología y los medios de comunicación, el desarrollo del transporte, entre otros, permiten problematizar las concepciones dicotómicas de espacio rural y urbano; sin embargo, a pesar de haberse estrechado las relaciones, la diferencia entre estos contextos sigue existiendo en términos de ingreso, incidencia de pobreza y oportunidades, especialmente en las áreas rurales más dispersas y apartadas de los centros urbanos (Kay, 2009).

\section{LAS DESIGUALDADES EN EL CORDÓN HORTÍCOLA DE SANTA FE: LA SITUACIÓN DE LAS FAMILIAS DE PEQUEÑOS PRODUCTORES}

En las últimas dos décadas, en el campo argentino, sucedieron cambios vertiginosos a partir de la expansión del monocultivo de granos - fundamentalmente de soja transgénica- para la exportación, proceso que se consolidó primero en la región pampeana y con el avance de la frontera agrícola se ha ido expandido hacia otras zonas, al tiempo que presenta una fuerte semejanza con las transformaciones desplegadas en el sur de Brasil, el oriente paraguayo y boliviano, $y$ Uruguay (Hocsman, 2014).

La emergencia de un nuevo modelo agrario, basado en procesos de innovación tecnológica, apertura externa y cambios en las formas de regulación de la producción y la distribución de la riqueza, generó un escenario de crecientes dificultades para la supervivencia de la llamada producción familiar, incluso en la provincia de Santa Fe, situada en el corazón de la llamada pampa gringa (Gras, 2012). En esa línea, en el agro pampeano se conjugan procesos de consolidación de pooles de siembra y de expulsión de productores cuya modalidad más significativa la encarna la figura del rentista: estos sujetos retienen la propiedad de la tierra pero relegan el control de la producción y pasan a percibir un ingreso bajo la forma de renta de la tierra (Rosati y Masello, 2013).

Este proceso de desaparición de explotaciones adquiere características específicas en el caso de la horticultura. El cordón o cinturón hortícola de la ciudad de Santa Fe está comprendido entre cuatro núcleos urbanos: Santa Fe, Ángel Gallardo, Monte Vera y Recreo; se caracteriza por las óptimas condiciones del clima y el suelo que permiten cultivar una gran variedad de hortalizas durante todo el año (figura 1). La superficie de tierras destinadas a la producción hortícola en 2005 era de aproximadamente 1800 hectáreas, cifra que representa un $50 \%$ menos de la cantidad utilizada 25 años atrás y significa una disminución promedio de 50 hectáreas por año (Bouzo et ál., 2005). Los estudios oficiales aportan números en el mismo sentido: entre 2001 y 2006 , la superficie ocupada con horticultura cayó un $57 \%$ y la cantidad de productores disminuyó un $42 \%$ en el mismo período, de 288 a 166 productores (Ministerio de la Producción del Gobierno de Santa Fe, 2009). 
FIGURA 1

MAPA DEL CORDÓN VERDE DE LA CIUDAD DE SANTA FE, ARGENTINA

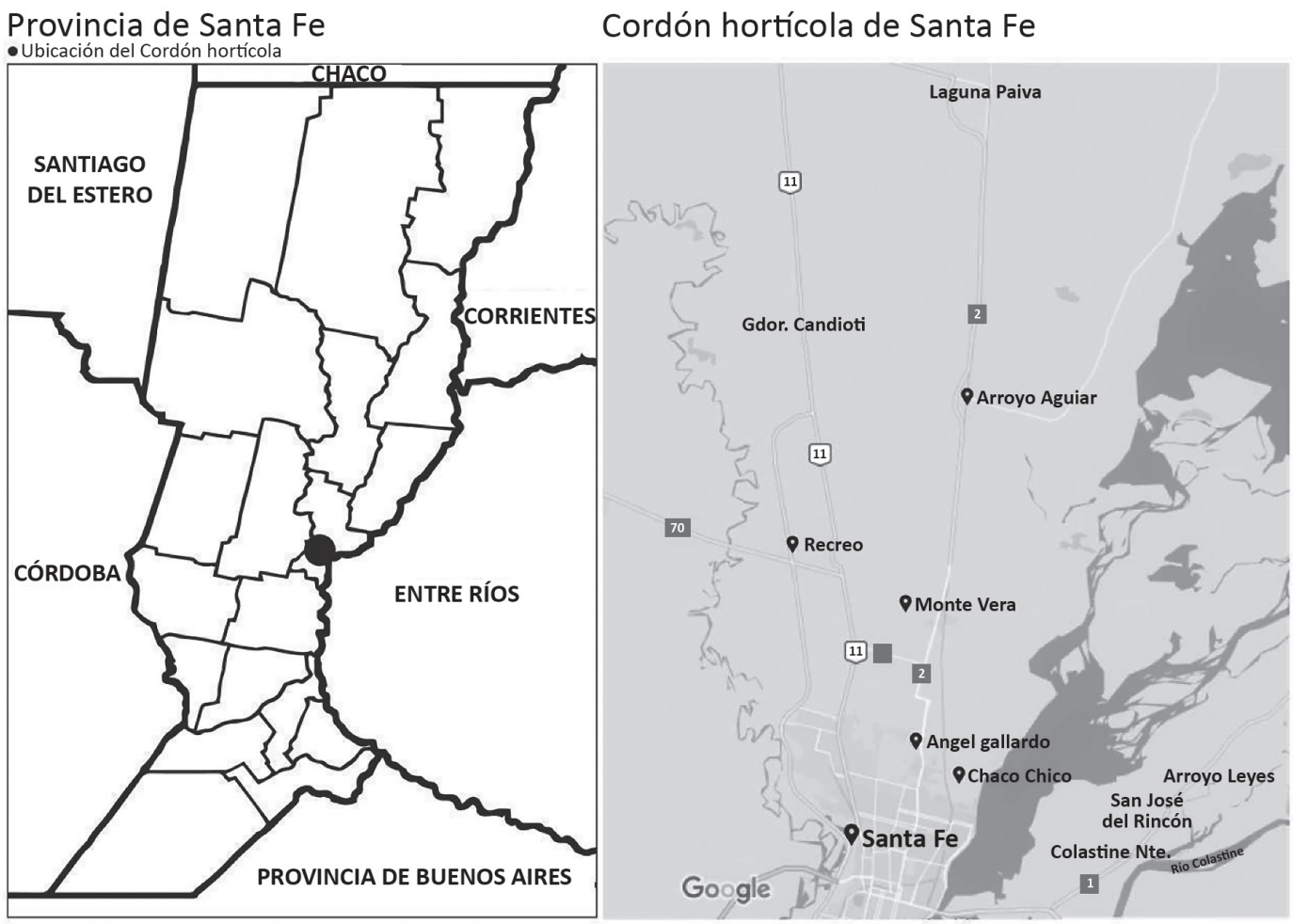

Fuente: Elaboración propia a partir de Google maps.

Esta paulatina disminución de la producción hortícola en la zona se pone de manifiesto en los relatos de los pequeños productores entrevistados. Juan tiene 57 años, ha nacido en Bolivia y desde mediados de la década de 1980 reside en las afueras de la ciudad de Recreo con su familia. En las últimas horas de la tarde, mientras trabajaba en su quinta, expresó su extrema preocupación por la notoria disminución de la actividad:

Quedamos muchos menos acá, muchos dejaron. Antes, cuando yo vine, este campo estaba lleno de tomates de época, ése también. Había gente de todos lados, de acá del norte de Santa Fe, del Chaco decían que había, de Bolivia había. A esta hora había un movimiento de camiones que venían de Buenos Aires, tres, cuatro, pasaban cargando mercaderías por las quintas, pero ahora se perdió. Escuchen el silencio que hay (González, comunicación personal, agosto de 2016).

Cuando se explica esta considerable disminución, los estudios coinciden al señalar que el creciente precio internacional de cereales y oleaginosas de exportación alentó a muchos productores, sobre todo a quienes poseían mayor cantidad de tierras, a abandonar la producción de hortalizas de consumo interno. También se menciona la creciente competencia de la producción de otros centros del país con mayor acceso a las tecnologías. La inundación de 2003 que afectó a más del 90\% de los cultivos y otros fenómenos climáticos significaron pérdidas 
históricas para los productores (Bouzo et ál., 2005). La referente de una de las organizaciones de productores y productoras, sin embargo, lo atribuye principalmente a la creciente urbanización y valoración de la tierra.

La situación de la producción hortícola es muy sensible, sobre todo si se le suma la especulación inmobiliaria (...) y los loteos para viviendas. La ciudad de Santa Fe va creciendo hacia el norte y las ciudades y comunas aledañas también van avanzando sobre los periurbanos, comiéndose los cordones verdes donde se producía el alimento. Y todo obviamente sucede sin una planificación urbana que tenga en cuenta las voces $y$ los intereses de todos (Lipozky, comunicación personal, agosto de 2016).

Las condiciones de vida y trabajo en las quintas no son homogéneas, sino que existen diferencias entre dos grupos distintos de productores del cordón. En primer lugar, se puede identificar al grupo de los pequeños productores, que son en su mayoría descendientes de bolivianos que han llegado al país en las décadas de 1960 y 1970.

Nosotros trabajamos con dos agrupamientos de productores que son muy distintos. Los productores con los que yo tengo contacto son los más pequeños que están organizados en el consorcio La Verdecita: están muy poco capitalizados y generalmente no son dueños de la tierra, que es el principal escollo por la inestabilidad que genera a la hora de planificar la producción. En cambio, los otros productores, que se identifican más con la Sociedad de Quinteros, son propietarios, están más capitalizados y trabajan mayor cantidad de hectáreas. Este grupo generalmente se compone de descendientes de inmigrantes italianos, así como más del $90 \%$ de los productores nucleados en La Verdecita son bolivianos o descendientes de bolivianos. Esto no es siempre así, ya que también hay productores bolivianos que han logrado capitalizarse mucho, pero es casi una generalidad (...) Varios productores bolivianos también participan de otras organizaciones e incluso también van a la Sociedad de Quinteros, aunque no tomen decisiones (Páez, trabajadora del INTA, comunicación personal, noviembre de 2016).

Una de las jóvenes de las familias productoras entrevistadas es categórica al referirse a esta diferenciación entre los dos grupos de productores.

Ellos son los más grandes, en la mayoría son gringos, nosotros no tenemos relación con ellos. Porque La Verdecita es de los pequeños productores, de los que no pueden vivir solo de ir al mercado ${ }^{6}$. Ahí tenés que pagar derecho de piso. No sé si fueron, pero ahí te dan un pedacito así más o menos, como el grandor de la mesa. Y vos tenés que estar ahí, arreglártelas ahí. Y si no tenés movilidad no podés llegar (Gómez, comunicación personal, agosto de 2016).

Según la información más actualizada sobre la situación en el cordón hortícola, el $50 \%$ de los productores trabaja entre una y cinco hectáreas. En relación a la propiedad de la tierra, cabe destacar que del total de productores, solo el $31 \%$ es dueño del total de la tierra que produce, mientras un $8 \%$ posee una parte de las tierras y a la vez arrienda hectáreas adicionales. El $61 \%$ restante de las familias produce bajo la forma de arrendamiento o alquiler o lo hace bajo préstamo, comodato, en tierra fiscal o en sucesión (INTA, 2013). Entre los principales problemas que sufren los pequeños productores, nuestros informantes coinciden en

$6 \quad$ La entrevistada se refiere al legendario Mercado de Productores y Abastecedores de Frutas, Verduras y Hortalizas de Santa Fe, que fue fundado en 1980 por la Federación Nacional de Operadores de Mercados Frutihortícolas y actualmente posee 30 hectáreas. Pertenece al Grupo Mercado de Productores, integrado por dos sociedades anónimas: Servicios Personales y Mersfin. 
subrayar las irregularidades que existen en los contratos de alquiler y los abusos por parte de los propietarios.

Las familias productoras señalan que en el cinturón persiste la mediería, un contrato informal que, aunque según su denominación debería implicar el aporte y la distribución igualitaria de capital y producción entre socios, en la práctica disfraza una relación desfavorable entre los trabajadores y el propietario de la tierra (Benencia, 1992; Benencia y Quaranta, 2003) ${ }^{7}$. La irregularidad de estas situaciones deja siempre al pequeño productor "en desventaja $y$ sin poder pensar a futuro porque no saben si mañana a esas tierras las van a lotear para viviendas, si los van a echar $y$ van a tener que irse a otro lado" (J. Páez, trabajadora del INTA, comunicación personal, noviembre de 2016). Así, las vulnerabilidades de muchas familias productoras en gran parte se explican por la falta de acceso a la tierra.

La mayoría somos bolivianos o de familia boliviana y muchos se han vuelto. En el 2003 o después de otras inundaciones o pedradas, muchos patrones despachaban a la gente con el boleto. Se querían volver a Bolivia y entonces el dueño de la tierra les pagaba el boleto y nada más. Muchos con tal de irse aceptaban esas condiciones, como los hermanos de mi marido, $y$ ahí se fueron disminuyendo las quintas (Sinfín, comunicación personal, septiembre de 2016).

$7 \quad$ En noviembre de 2003, el ex presidente Néstor Kirchner sancionó el decreto 1056/03 que establece la prohibición del sistema de mediería y deja sin efecto otro decreto sancionado en 2001, que establecía las características del Contrato de Mediería Frutihortícola presentando al productor mediero como "sujeto agrario autónomo". Actualmente, dado el vacío en la reglamentación, la mediería hortícola puede ser amparada como un contrato asociativo de acuerdo a la Ley 13.246 de Arrendamientos y Aparcerías Rurales (García y González, 2014).
La falta de acceso a la tierra, a su vez, puede señalarse como uno de los aspectos que dificultan que las pesonas jóvenes continúen con la labor de sus padres.

Si pienso, desde que me acuerdo cuando era chiquita hasta ahora, te puedo decir que muchos quinteros de antes no están más. Y ya muy pocos quinteros veo y muchos quinteros que veo son los más viejos que quedaron, los que conoce mi papá. Y de los hijos pocos quedan, de esta generación, de la mía, ya muy poco. Es que se van. Se van porque también está más difícil que antes. A veces se quedan a trabajar con el papá y la mamá pero no suelen arrancar su producción propia, no se animan a arrancar una nueva. Acá tenés que esperar tres meses o más para tener una cosecha $y$ a veces te puede pasar que el agua, una tormenta, unas piedras, te arruinan todo (...). Y ahí tenés que aguantar y para el alquiler tenés que estar al día, a ellos no les importa qué te pasó, nada (González, comunicación personal, agosto de 2016).

Con respecto a las condiciones de vida $y$ trabajo de los pequeños productores, la zona en que residen y trabajan las familias no tiene agua corriente $y$ en los hogares existen pozos de donde se extrae agua de napas subterráneas. El alumbrado público es insuficiente y las vías de acceso no cuentan con mantenimiento en ocasión de lluvias, lo cual dificulta el ingreso o salida de las quintas. Por otra parte, los productores no han alcanzado alto grado en la tecnificación del trabajo, por lo que siembran de forma manual: solo una de las familias estudiadas posee una sembradora mecánica y un tractor que ha logrado adquirir a partir de ahorros generados en actividades extra a la huerta familiar. En cuanto a la movilidad, el vehículo destinado a trasladar la verdura, sin preparación específica para el traslado de producción hortícola ni habilitación de los organismos de sanidad, suele ser el único vehículo del hogar, a excepción de algunas motos que poseen las personas jóvenes. 


\section{EL TRABAJO: ENTRE LA QUINTA Y EL MUNDO}

Para estudiar las prácticas y representaciones de las juventudes de familias hortícolas en torno al trabajo, se parte de una concepción amplia que permite tomar en cuenta no solo el empleo que algunos integrantes de las familias desarrollan en forma autónoma o en relación de dependencia fuera del hogar, sino fundamentalmente el trabajo familiar que se lleva a cabo en las quintas de producción hortícola, incluyendo el trabajo doméstico $y$ de cuidado ${ }^{8}$. Las viviendas de las familias hortícolas suelen estar en el mismo predio que las quintas, por lo que muchas veces el trabajo en la huerta en el que participa toda la familia no se diferencia del todo del trabajo doméstico. Las tareas se cruzan y se confunden; el "estar en la quinta" incluye tareas estrictamente ligadas a la producción, aunque en otras ocasiones, cuando los límites entre la quinta y el hogar se borran, puede contemplar tareas relacionadas con el trabajo doméstico y de cuidado, asumido exclusivamente por las mujeres de la casa.

En las familias hortícolas se advirtió un fuerte involucramiento de niñas, niños y jóvenes en diferentes tareas vinculadas a la producción, lo que se expresa en los relatos sobre la infancia.

Más de chica me gustaba limpiar y estar en la quinta. Cuando fui creciendo y fui creciendo, aprendí yo sola ahí (...). Mi hermano, el varón, era el que más ayudaba pero yo me ponía a la par de ellos cuando tenía que cargar repollo, el que te piden suelto. $\mathrm{O}$ ir tirando, viste,

8 Se conciben a las familias como unidades domésticas que, aunque suelen estar asociadas a la familia nuclear o el hogar, refieren a la organización económica propia de la economía popular que se caracteriza por buscar la reproducción de la vida de sus miembros y puede estar fundada en relaciones de parentesco, étnicas o de afinidad (Coraggio, 2003). En este sentido, se identifican jóvenes que, aunque no comparten la vivienda con su familia de origen y han conformado un nuevo hogar, integran una unidad doméstica con sus padres y hermanos porque siguen trabajando en la huerta familiar $y$ son referenciados al interior de este núcleo como "hija o hijo" y "hermano o hermana". de arriba a abajo, la verdura al camión o para pasarle a mi papá. Era igual el trabajo de mujer o varón, total teníamos que ir a ayudar. Igual que mi papá, que desde los siete años que trabaja en la quinta y como mi mamá (González, comunicación personal, agosto de 2016).

Para las personas adultas de las familias, el trabajo durante la infancia aparece relacionado con la necesaria transmisión de los saberes hortícolas: "los hacíamos trabajar en la quinta para que vayan aprendiendo, igual que como aprendimos nosotros", "no lo hacíamos para explotarlos a ellos, era para enseñarles, era todo una cosa en familia" (A. Sinfín, comunicación personal, agosto de 2016). En otros casos, la "ayuda de los chicos" además se relaciona con una necesidad material. Desde la infancia se identifica una tensión entre el trabajo en las quintas y la inclusión en la educación formal, aunque las familias garantizan la educación primaria de sus hijos. La escolaridad secundaria de la población jóven, en cambio, presenta diferentes trayectorias:

Yo terminé en el EEMPA ${ }^{9}$ porque antes había dejado la secundaria, terminé ahí porque sin secundaria no hacés nada, pero nosotros también teníamos mucho que hacer en casa y es así. Muchas de mis compañeras tuvieron que abandonar la escuela porque ayudaban mucho en la casa, en su familia solo vivían de la quinta y eran muchos, tenían que ayudar siempre, mucho (Torres, comunicación personal, septiembre de 2016).

En la vida de las personas jóvenes que han finalizado o abandonado la educación secundaria, el trabajo vinculado a la producción hortícola se complementa con otras actividades. Si los niños y las niñas parecen realizar el mismo tipo de tareas durante la infancia, a medida que transcurren los años se comienzan

$9 \quad$ Se refiere a la Escuela de Enseñanza Media Para Adultos, una modalidad de educación secundaria que facilita la finalización del nivel a personas mayores de 18 años en la provincia de Santa Fe. 
a diferenciar ciertos roles entre varones y mujeres. Mientras que los jóvenes varones suelen encaminarse a realizar changas ${ }^{10}$ de albañilería, trabajar como peones de campo o en relación de dependencia en negocios o industrias de la zona, las mujeres buscan continuar sus estudios - se destaca la elección de la carrera docente o enfermería y la realización de cursos cortos ofrecidos por instituciones de formación en las ciudades próximas-, además de realizar trabajo doméstico y de cuidado.

En el trabajo hortícola también se observan diferencias. Es significativa la participación de las jóvenes mujeres junto a sus madres en tareas como la recolección, el lavado de la verdura y el agregado de valor a la producción, así como, su presencia en puestos de venta en las ferias $y$ talleres brindados por organizaciones de productores y productoras de la zona ${ }^{11}$, mientras los varones están mayormente ligados a la carga y al traslado de la producción, la venta en el mercado central de productores, la utilización del tractor y actividades que demandan mayor uso de fuerza física. Sin embargo, tanto jóvenes varones como mujeres no perciben una remuneración económica en base a la cantidad de horas trabajadas, sino que, en palabras de una productora, "todo va a la misma bolsa $y$ después de acuerdo a las necesidades. Por ahí a los chicos no los podés hacer conformar con poco, pero entienden" (N. González, comunicación personal, septiembre de 2016).

La población joven construye sus representaciones sobre el trabajo hortícola en estrecha relación con el momento de producción en las quintas, sin referenciar tareas relacionadas con otros aspectos del proceso, como es la venta en la feria, los cursos y talleres de formación o el valor agregado a las verduras $y$ hortalizas. La producción hortícola, entonces,

10 Es un término utilizado de manera informal en Argentina para referir al trabajo temporal, a un empleo que tiene una duración definida, generalmente de corto plazo.

11 Estos talleres incentivan procesos de valor agregado y diversificación de la producción mediante la realización de mermeladas caseras, conservas, bandejas de verdura fresca, huevos, plantines $y$ quesos. es relacionada con un trabajo exclusivamente ligado a la tierra, marcado por el cansancio, la imprevisibilidad, la desolación en las quintas $y$ la constante descripción de las dificultades sufridas por sus familias. Así, en los relatos de las mujeres, su propio trabajo está invisibilizado al ser referenciado como una "ayuda a la familia" o como tareas que realizan en los tiempos libres o hacia el final de la jornada. Una joven, aunque vive con su pareja $y$ en la descripción de las actividades que realiza solo menciona el estudio y la producción de plantines, sigue vinculada al trabajo con su familia de origen: participa de la venta de las verduras, ayuda a trasladar los productos a la feria $y$, cuando no tiene que estudiar o en épocas de mucho trabajo en la quinta, incluso asiste a su madre en la recolección.

En lo que respecta a las expectativas laborales a mediano o largo plazo, ni mujeres ni hombres jóvenes imaginan un futuro fuertemente vinculado a la actividad hortícola, lo que a su vez se relaciona con dos afirmaciones que pueden identificarse en sus relatos: si por momentos remiten a la dureza de la vida y el trabajo inherentes a la actividad hortícola para expresar una toma de posición y erigirse como protagonistas de la decisión de elegir un camino diferente al de sus familias, en otras ocasiones pareciera que son las condiciones en las que se encuentra la producción hortícola y la situación desfavorable de sus familias las que expulsan a estas juventudes hacia otros rumbos porque "no hay trabajo para todos" o "la quinta no tiene mucha salida hoy, no queda otra que buscarse un sueldo seguro".

\section{MOVILIDADES ESPACIALES: IR Y VENIR}

Las prácticas y las representaciones de las juventudes que han nacido, habitan y pasan gran parte de sus vidas en lo que llaman "el campo" no pueden comprenderse, sin referir a los desplazamientos periódicos hacia "la ciudad". Una semana cualquiera, María recorre alrededor de 4 kilómetros para dirigirse a la ciudad de Recreo, en cuyo ejido rural se encuentra la casa $y$ la quinta en la que vive $y$ trabaja; asimismo, al menos una vez a la semana, transita 9 kilómetros hacia la zona norte de la ciudad de 
Santa Fe, donde se realizan las reuniones de las organizaciones de productores y productoras, $y$ los fines de semana participa de una feria en el centro, a 15 kilómetros de su vivienda. Además, se dirige a Santa Fe para recibir atención médica en el sistema público de salud y "dejar currículums en los negocios para trabajar de vender ropa", pero fundamentalmente se trata de desplazamientos realizados con regularidad, de trayectos integrados a la rutina.

Es interesante destacar que los desplazamientos que protagonizan tanto jóvenes mujeres como varones se relacionan con el hecho de que complementan el trabajo en las huertas, ubicadas en sus viviendas en zonas rurales, con otras actividades como estudiar, trabajar en relación de dependencia y participar de cursos, talleres, ferias o reuniones en distintas localidades intermedias (Recreo, Laguna Paiva y Monte Vera) y en una gran ciudad como Santa Fe. Las juventudes no cambian su lugar de residencia, no abandonan el hogar familiar ni migran definitivamente a los centros urbanos en busca de nuevas oportunidades, sino que se mueven a lo largo de una misma jornada con diversa periodicidad y en función de objetivos puntuales, incluso cuando esto les requiere trasladarse con mucha frecuencia entre los distintos puntos que configuran su mapa cotidiano:

Voy a la Facultad a Santa Fe la mañana y a la tarde. Curso de lunes a viernes, así que a veces voy $y$ vuelvo dos veces. Hay días que llego a comer y ya tengo que salir otra vez. Como y me voy porque a las 4 entro otra vez y tengo que tomar el colectivo (...). Depende el día y el cole que agarro, pero a veces son como dos horas hasta que llego a casa (Torres, comunicación personal, septiembre de 2016).

Así, las juventudes se desplazan en torno a una zona común que conforma lo que se identifican como sus espacios de vida: la porción de espacios, que exceden sus lugares de residencia, por los que transcurren en sus interacciones cotidianas o periódicas y realizan las distintas actividades de sus vidas (Courgeau, 1990; Domenach y Picouet, 1990).
La frecuencia y la regularidad con que las personas jóvenes se trasladan por el cordón verde de Santa Fe marca una diferenciación entre sus trayectos cotidianos y los de las personas adultas de las familias hortícolas. Estos últimos tienden a pasar más tiempo dentro de las quintas y resolver el cúmulo de actividades de sus vidas en ese ámbito, incluso cuando los adultos complementan la producción familiar con trabajos en relación de dependencia fuera del hogar y las adultas protagonizan la venta en las ferias y los talleres de las organizaciones de productores $y$ productoras. Sin embargo, las historias de vida de la generación anterior también han estado marcadas por movilidades espaciales, aunque aquí podrían identificarse trayectorias de otro tipo: migraciones de Bolivia y traslados entre distintas localidades de la zona que implicaron cambios temporales de residencia en busca de nuevas oportunidades laborales o escapando de situaciones adversas, como las inundaciones en 2003.

Si en la dimensión del trabajo las diferencias y las desigualdades entre jóvenes mujeres y varones son significativas, en lo que respecta a las movilidades espaciales, en cambio, pueden señalarse solo algunas especificidades en los modos de desplazamiento: la vulnerabilidad de las mujeres se expresa en que dependen de los varones; sus parejas y/o sus padres aparecen referenciados como quienes las "llevan" y las "acompañan" hasta las paradas de transporte público o sus lugares de destino por la "inseguridad". En palabras de una joven que sufrió un robo llegando a su casa: "Yo decía 'bueno, mi papá está trabajando, no lo molesto'. Pero tengo un kilómetro y medio del colectivo a mi casa. Bueno, ahora dependo más de él. Cuando salgo lo llamo, cuando llego, lo llamo".

Hasta aquí se ha referido a las crecientes interrelaciones que existen entre lo que las juventudes estudiadas nombran como "el campo" y "la ciudad" y los desplazamientos cotidianos que configuran sus espacios de vida entre "lo urbano" y "lo rural". Sin caer en concepciones dicotómicas entre campo y ciudad ya problematizadas, se debe atender a la persistencia de diferencias entre los dos espacios. De hecho, los desplazamientos mediante los 
cuales las juventudes rurales se mueven entre estos contextos, que en sus relatos se constituyen como puntos distantes $y$ diferenciados en el mapa, refuerzan su identificación como espacios antagónicos. Así, el campo aparece como un lugar aislado, sin acceso a comodidades y servicios, sin oportunidades laborales $y$ de esparcimiento, mientras la ciudad se relaciona con las posibilidades laborales, donde "tenés todo a mano" y es "más fácil llegar a un lugar". En otro orden, el campo es para las juventudes un lugar "tranquilo", "pacífico", "natural", donde se sienten cómodos y a gusto; la ciudad, en cambio, es asociada a la contaminación, el ruido, el humo y lo desconocido.

En la ciudad, viste, vivís sobre la calle $y$ te pasan los autos. Y el olor del combustible no me gusta tampoco. Porque tenés algún vecino y por ahí querés escuchar música fuerte a la hora de la siesta cuando limpiás, por ejemplo, y no le gusta al de al lado. Yo sabía ir a la casa de mis compañeras en Recreo y ahí estaban: 'el vecino esto', 'el vecino lo otro', 'bajá el volumen' (...). Pero en Recreo tenés más cosas para hacer también, como Santa $\mathrm{Fe}$, que tenés de todo y además está todo a mano (González, comunicación personal, agosto de 2016).

Si bien, en el apartado anterior se ha señalado que gran parte de las representaciones sobre el futuro de las personas jóvenes rurales los aleja de la actividad hortícola, estas expresiones se encuentran en tensión con cierta aprehensión y deseos de permanecer en el campo.

No, no viviría en Santa Fe. Yo cuando el colectivo va llegando a Santa Fe me doy cuenta porque me empieza a doler la cabeza. No sé cómo es pero desde que entro hasta que me voy me duele la cabeza. Ya cuando me vuelvo acá no se siente el olor a humo, qué sé yo, a nafta de los vehículos, es re tranquilo, es muy tranquilo (...). Por ahí me voy capaz que una hora y ya me quiero volver. Quiero estar tranquila porque yo acá estoy tranquila, nadie me molesta, ni incluso se escuchan... Y acá no escucho nada, solamente los animales, es muy raro que pase un vehículo acá, no es muy transitado (Gómez, comunicación personal, agosto de 2016).

\section{CONSIDERACIONES E INDAGACIONES FINALES}

A lo largo de este trabajo se han planteado las interrogantes acerca de las prácticas $y$ representaciones de la población joven rural perteneciente a familias de pequeños productores hortícolas del cinturón verde de la ciudad de Santa Fe. En función de lo estudiado acerca de las dimensiones abordadas en este artículo - el trabajo y las movilidades espaciales - en este estudio se recuperan algunas tensiones que a su vez invitan a pensar en una serie de interrogantes para futuras investigaciones.

En primer lugar, se señala una tensión entre los modos en que las personas jóvenes representan el trabajo hortícola —que aparece exclusivamente ligado a la tierra, marcado por el cansancio, la imprevisibilidad y la desolación en las quintas - y el hecho de que las mujeres jóvenes suelen realizar tareas relacionadas con otros momentos del proceso como es la venta en la feria, los cursos, talleres de formación y agregado de valor desarrollados por las organizaciones de productores y productoras.

Una segunda tensión se relaciona con las expresiones de la población acerca de sus expectativas laborales a mediano o largo plazo, en las que no imaginan un futuro fuertemente vinculado a la actividad hortícola: afirmaciones que remiten a la dureza de la vida y el trabajo inherentes a la actividad para expresar una toma de posición y erigirse como protagonistas de la elección de un camino diferente al de sus familias. Se contradicen con relatos de expulsión, que relacionan las condiciones en las que se encuentra la horticultura y la situación desfavorable de sus familias con sus proyecciones de vida lejos de las quintas.

Por otro lado, se ha señalado que las juventudes estudiadas no cambian su lugar de residencia, no abandonan el hogar familiar ni migran definitivamente a los centros urbanos 
en busca de nuevas oportunidades, sino que se trasladan con diversa periodicidad y en función de objetivos puntuales en torno a una zona común que conforma sus espacios de vida. Se identifica una tercera tensión entre estas movilidades que constantemente vinculan "lo rural" y "lo urbano", estrechando la relación entre ambos contextos, y el hecho de que estos desplazamientos, que en sus relatos se constituyen como puntos distantes $y$ diferenciados en el mapa, refuercen su identificación como espacios antagónicos: el campo aparece asociado al aislamiento, la falta de acceso a servicios, comodidades, oportunidades laborales y esparcimiento, mientras la ciudad se relaciona con las posibilidades laborales $y$ la accesibilidad; en otro orden, el campo es un lugar "tranquilo", "pacífico", "natural", donde se sienten cómodos, mientras la ciudad es asociada a la contaminación, el ruido, el humo y lo desconocido.

Este estudio se realiza a partir del reconocimiento de las múltiples diferencias $y$ desigualdades de género que tiñen las dimensiones abordadas. En las páginas que preceden se identificaron a las jóvenes mujeres rurales como un grupo que podría nombrarse particularmente vulnerable. Aquí se presenta el desafío de profundizar en la pregunta acerca de los modos en que las múltiples vulnerabilidades se conjugan en el grupo abordado, lo que amerita trabajos posteriores - que podrían realizarse desde una perspectiva interseccional (Anthias, 2006; Davis, 2008; Phoenix y Pattynama, 2006) - que avancen en la indagación de cómo se imbrican las variables de género, generación, clase, pertenencia territorial e incluso étnica, en función de la ascendencia boliviana y aymara de la mayoría de las personas jóvenes.

Finalmente, se identificó otra línea de futuras indagaciones que permitan profundizar este estudio. Se indicó la participación de las mujeres en instancias de formación y ferias realizadas en el marco de las organizaciones de productores y productoras de la zona, espacios que les permiten ensayar alternativas de producción y transitar por nuevos lugares. Resta indagar los modos en que, si bien, la participación en estas organizaciones no asegura la permanencia en el campo y en la actividad hortícola, abre un abanico de posibilidades de formación y distribución de la producción que incluye nuevas herramientas para "ir y venir" al "campo".

\section{REFERENCIAS}

Anthias, F. (2006). Género, etnicidad, clase y migración: interseccionalidad y pertenencia translocalizacional. En P. Rodriguez, Feminismos periféricos. Granada: Editorial Alhulia.

Benencia, R., y Quaranta, G. (2003). Reestructuración y contratos de mediería en la región pampeana argentina. European Review of Latin American and Caribbean Studies, 74, 65-84.

Benencia, R. (1992). Transformaciones en el mercado de trabajo: la mediería en la horticultura bonaerense. Estudios del Trabajo 2 (3), 124-149.

Bouzo C., Favaro, J. C., Pilatti, R., y Scaglia, E. (2005). Cinturón hortícola de Santa Fe: Descripción de la zona y situación actual. Revista Fave-Sección Ciencias Agrarias, revista de la Facultad de Ciencias Agraria de la Universidad Nacional del Litoral, 4 (1-2), 63-69.

Braslavsky, C. (1986). La juventud argentina: informe de situación. Buenos Aires: Centro Editor de América Latina.

Bruniard R. y otros (Coord.) (2007). Educación, desarrollo rural y juventud. La educación de los jóvenes de provincias del NEA y NOA en Argentina. Buenos Aires: UNESCO-IIPE, FIDA, SAGPA.

Carneiro, M. (1999). O ideal rurbano: campo e cidade no imaginário de jovens rurais. En F.C. Teixeira da Silva, R. Santos, L.F.C. Costa (Orgs.), Mundo Rural e Política: ensaios interdisciplinares. Rio de Janeiro: Ed. Campus/Pronex.

Chaves, M. (2005). Juventud negada y negativizada: representaciones $y$ formaciones discursivas vigentes en la Argentina contemporánea. Revista Última Década, 13(23), 9-32.

Chaves, M. (2009). Estudios sobre juventudes en Argentina. Hacia un estado 
del arte/2007. La Plata: Editorial de la Universidad Nacional de La Plata.

Coraggio, J. L.(2003). Qué significa pasar de la economía popular a la economía del trabajo. Proposta, 30, 12-20.

Courgeau, D. (1990). Nuevos enfoques para medir la movilidad espacial interna de la población. Notas de Población, 18(50), $55-75$.

Davis, K. (2008). Intersectionality as buzzword. A sociology of science perspective on what makes a feminist theory successful. Feminist Theory, 9(1), 67-85.

Dirven, M. (dir.); Echeverri, R.; Sabalain, C.; Rodriguez, A.; Candia, D.; Peña, C. y Faiguenbaum, S. (2011). Hacia una nueva definición de "rural" con fines estadísticos en América Latina. Serie: Documentos de Proyectos, 397. Santiago: CEPAL.

Domenach, H. y, Picouet, M. (1990). El carácter de la reversibilidad en el estudio de la migración. Notas de Población, 40, 49-69.

García, M. y González, E. (2014). Mediería en la horticultura: Legislación necesaria - aunque insuficiente - para un acuerdo asociado. Ponencia presentada en la VIII Jornadas de Sociología de la UNLP, 3 al 5 de diciembre de 2014, Ensenada, Argentina. En Memoria Académica. Recuperado de http://www.memoria. fahce.unlp.edu.ar/trab_eventos/ev.4746/ ev.4746.pdf

Garayo, J. (1996). La sociedad rural en el final de siglo. Inguruak. Revista Vasca de Sociología y Ciencia Política, 16, 61-80.

González, C., y Román, M. (2012). Juventud y migraciones: vivencias, percepciones, ilusiones: un estudio en NOA y NEA. Buenos Aires: Ministerio de Agricultura, Ganadería y Pesca.

Gobierno de la Provincia de Santa Fe. (2011). Politicas locales de juventud en Santa Fe 1. Recuperado de https://www. santafe.gov.ar/index.php/web/content/download/136904/676236/file/ Pol\%C3\%ADticas\%20locales\%20de\%20 juventud\%20en\%20Santa\%20Fe.pdf
Graziano Da Silva, J., y del Grossi, M. E. (2001) [en línea]. A evolução do emprego não agrícola no meio rural brasileiro. Projeto Rurbano. Recuperado de www.eco.unicamp. br. projeto /rurbano

Gras, C. (2012). Cambio agrario y nueva ruralidad: Caleidoscopio de la expansión sojera en la región pampeana. Trabajo y sociedad, 18, 07-24.

Guber, R. (2001). La etnografía. Método, campo y reflexividad. Buenos Aires: Norma.

Hocsman, L. (2014). Horizonte para la producción campesina y agricultura familiar en el modelo agroalimentario hegemónico mundial. Visión desde el Cono Sur. En F. Hidalgo y otros Agriculturas campesinas en Latinoamérica. Propuestas y desafíos. Quito: Editorial IAEN.

Instituto Nacional de Estadística y Censos (INDEC). Glosario. Recuperado de http:// www.indec.gob.ar/glosario.asp

Instituto Nacional de Tecnología Agropecuaria (InTA). (2013) Censo Hortícola 2012 de la Agencia de Extensión Rural Santa Fe del INTA. Publicación técnica nro. 62 de la Agencia INTA de Extensión Rural Santa Fe, Monte Vera. Recuperado de http:// inta.gob.ar/sites/default/files/scripttmpinta_censo_frutihorticola_santafe_2012.pdf

Kay, C. (2009). Estudios rurales en América Latina en el periodo de globalización neoliberal: ¿una nueva ruralidad? Revista mexicana de sociología, 71(4), 607-645.

Kessler, G. (2007). Juventud rural en América Latina. Panorama de las investigaciones actuales. En Rogelio Bruniard y otros (Coord.). Educación, desarrollo rural y juventud. La educación de los jóvenes de provincias del NEA y NOA en Argentina. Buenos Aires: UNESO-IIPE, FIDA, SAGPA.

Klein, E. (1992). El Empleo rural no agrícola en América Latina. Documento nro. 364. Santiago: PREALC/OIT.

Margulis, M., y Urresti, M. (1996). La juventud es más que una palabra. En M. Margulis (ed.), La juventud es más que una palabra. Buenos Aires: Biblos. 
Margulis, M., y Urresti, M. (1998). La construcción social de la condición de juventud. En M. Margulis y H. Cubides. Viviendo a toda. Jóvenes, territorios culturales y nuevas sensibilidades. Bogotá: Siglo del Hombre Editores.

Matijasevic Arcila, M. T., y Ruiz Silva, A. (2013). La construcción social de lo rural. Revista Latinoamericana de Metodología de la Investigación Social-ReLmIS, 5, 3. Recuperado de http://www.relmis.com.ar/ ojs/index.php/relmis/article/view/60

Ministerio de Producción del Gobierno de Santa Fe. (2009). Cadena frutihortícola santafesina: una nueva visión para la producción y el desarrollo. Recuperado de_https:// www.santafe.gov.ar/index.php/web/content/ download/66061/320661/file/descargar.pdf

Moreira, R. (2003). Extensão Rural na contemporaneidade: cultura e política. En R. Thornton, y G. Cimadevilla, La Extensión Rural en Debate. Concepciones, retrospectivas, cambios y estrategias para el MERCOSUR. Buenos Aires: Ediciones INTA.

Pérez Islas, J.A. (2004). Historizar a los jóvenes. Propuestas para buscar los inicios. En J.A. Pérez Islas y M. Urteaga (coords.). Historias de los jóvenes en México. Su presencia en el siglo $X X$ (pp.17-32). México: sep/imj-Ciejuv/agn.

Pérez, J. (coord.) (2000). Jóvenes e instituciones en México. 1994-2000. México: SEP-Instituto Mexicano de la Juventud.

Phoenix, A., y Pattynama, P. (2006). Interseccionality. European Journal of Women's Studies, 3 (3), 187-192.
Quirós, J. (2015). Etnografiar mundos vívidos. Desafíos de trabajo de campo, escritura y enseñanza en antropología. PUBLICAR-En Antropología y Ciencias Sociales, (17).

Roa, M. L. (2017). Juventud rural y subjetividad. La vida entre el monte y la ciudad. Ciudad Autónoma de Buenos Aires: Grupo Editor Universitario.

Rockwell, E. (2009). La experiencia etnográfica: historia y cultura en los procesos educativos. Buenos Aires: Paidós.

Rosati, G., y Masello, D. (2013). Cambios en la estructura social agraria pampeana. Un acercamiento a la caracterización de los pequeños propietarios rentistas del sur de Santa Fe. Pampa: Revista Interuniversitaria de Estudios Territoriales, 9, 149-177.

Saltalamacchia, H. (1989). La juventud hoy: un análisis conceptual. Revista Ciencias Sociales, 28.

Schmuck, M. E. (2018). Juventudes en plural, territorios en transformación. Hacia un estado del arte de los estudios sobre juventudes rurales en Argentina. Revista Pós, dossiê: Jovens pesquisadores latinoamericanos, 14.

Weller, J. (1997). El empleo Rural no Agropecuário en el istmo Centroamericano. Revista de la Cepal, 62, 75-90.
Fecha de ingreso: 16/08/2018

Fecha de aprobación: 05/11/2018 